\title{
LA CRISIS FINANCIERA E INSTITUCIONAL DEL AYUNTAMIENTO DEL DISTRITO NACIONAL DE LA REPUBLICA DOMINICANA
}

CESAR PEREZ*

\section{Introducción}

Con el presente trabajo pretendemos llamar la atención sobre uno de los más apremiantes problemas de las autoridades edilicias del ADN: la falta de recurso para enfrentar la demanda de los servicios de la población capitalina.

Tratamos de evidenciar la complejidad del problema y la necesidad de un enfoque, donde se insista sobre la incidencia de las ambigüedades institucionales que enrarecen el sistema político dominicano en la cuestión municipal.

La población, no sólo de la Capital, sino de otros municipios enfrenta graves problemas. Muchos de los servicios básicos son deficientes, importantes sectores de dicha población son excluidos del consumo de bienes tan preciados como la vivienda, el agua, la educación, la salud y el disfrute del ocio, etc.

La falta de recursos del Ayuntamiento, no sólo impide que se palien los problemas, sino que asistamos a un progresivo deterioro de las condiciones de vida en nuestras aglomeraciones urbanas, lo cual recurre al mismo paso con las protestas de un vasto sector de la población de los barrios más exclusivos de los servicios.

Investigaciones sobre el campo, mediante visitas y entrevistas con algunos funcionarios municipales, me llevan a la conclusión de que en la realidad hay

Facultad de Ciencias Sociales del INTEC. 
deseos de enfrentar el problema, pero trabas de orden institucional tienden a pesar más que los deseos y por lo tanto el problema difícilmente puede ser superado si esos obstáculos no son eliminados.

\section{Las fuentes de ingresos del Ayuntamiento del Distrito Nacional}

Es generalizada la percepción de que el principal problema del Ayuntamiento del Distrito Nacional es la insuficiencia cada vez más acentuada de recursos económicos para satisfacer las demandas de la población del territorio que administra.

Todos los incumbentes de la Sindicatura, lo primero que reclaman es fondos al Poder Ejecutivo, para tratar de resolver las exigencias de una población que crece de manera impresionante, aumentando al mismo tiempo sus expectativas y necesidades tanto reales como creadas.

El reclamo se hace una reiteración casi obsesiva, y quizás, entre otras, por esta razón no aparece pública la irracionalidad administrativa y la ineficincia en que se desenvuelve el ADN. * Además, del descuido que éste manifiesta en no practicar una gestión edilicia volcada hacia la ciudadanía para lograr la necesaria participación de ésta, para que junto a sus autoriades se incorpore a la búsqueda de recursos para solucionar los problemas del municipio.

La lucha por los recursos económicos se ha limitado al estrecho ángulo de las relaciones Presidente-Síndico, la cual es percibida por la población como una relación de poderes, de los cuales ella se siente excluida. La observan con peligrosa indiferencia.

El problema de los recursos económicos debe ser visto a partir de las razones de fondo que le dan origen. Debe enfocarse a la luz de las ambigüedades institucionales que afectan, en este caso, la fluidez del funcionamiento del sistema político.

A lo largo de toda la historia de la República Dominicana, la búsqueda de proyectos constitucionales y del establecimiento de un orden jurídico percibido como legítimo, ha sido preocupación de los grupos dominantes del país, todo esto, independiente de ocasionales expresiones contrarias hechas por uno que otro gobernante; o que todavía hoy las reglas no están suficientemente establecidas, ni mucho menos respetadas las pocas consignadas en la Constitución.

Por esto, no es de sorprender que en tanto que proyecto, algunas instituciones como este caso el $\mathrm{ADN}$, ha tenido un estatuto jurídico donde se consigna su autonomía y su capacidad de todo tipo de actos jurídicos para la

Ayuntamiento del Distrito Nacional. 
consecución de sus fines, entre los cuales está el de dar los servicios requeridos por la comunidad bajo su dirección.

Por ley, todas las ciudades del país son dirigidas por un Ayuntamiento, ei cual de acuerdo con la tradición de la administración municipal tiene autonomía frente al poder central.

La ciudad capital dominicana también tiene administración, la cual según la ley, es autónoma para realizar sus actos jurídicos y de funcionamiento interno; sin embargo, la peculiaridad del sistema político del país, entre otros factores, hace que esa autonomía sea limitada en lo relativo a la posibilidad de establecer arbitrios para recabar recursos económicos.

La centralización del poder político en la República Dominicana, la tradición presidencialista, le asigna al ADN una condición distinta de los gobiernos municipales del resto del país.

Ello así, porque a pesar de la importancia de la ciudad capital en última instancia se debe a su condición de espacio, de territorio donde se dan las actividades económicas y sociales más relevantes del país, el poder central la percibe no como una plaza, como un mercado con las prerrogativas de autodirigirse, sino como territorio donde se encuentra la sede del Gobierno.

Es así como la ciudad viene considerada de interés nacional, por ser dicha sede, y por tanto su territorio, su condición de ciudad al margen de otra consideración que sea ésta: Ciudad, no constituye la base económica para obtener sus recursos para administrarse, sino que ésta es administraq̣a en base a su status de capital.

Es claro que esto rompe toda tradición histórica de la administración municipal no sólo mundial sino de la propia Santo Domingo.

Desde 1844, hasta 1934, nuestra ciudad tenía una autonomía municipal, por lo menos jurídicamente.

En 1961, a raíz del ajusticiamiento de Trujillo, se le devuelve la autonomía, siendo ésta gobernada de acuerdo a la ley de municipios.

En 1966, con las leyes 40 y 624 sobre el establecimiento de arbitrio reducen considerablemente los ingresos de la institución edilicia, pues se prueba un subsidio bajo la estricta responsabilidad del Poder Ejecutivo.

Balaguer, en su concepción del poder centralizado, toma bajo su responsabilidad, la reconstrucción de la ciudad, haciendo de esa tarea uno de los más deseados imperativos de su gestión gubernamental.

La ley 6232 faculta al Consejo Nacional de Planificación, la dirección y ejecución de los planes reguladores de la ciudad, lo cual significó una virtual colocación del ADN en posición de simple administración en términos burocráticos de los planes que guiaban la organización de la trama urbana de la Capital. 
Mediante la ley 180, el Consejo Nacional de Desarrollo, organismo adscrito al Secretariado Técnico de la Presidencia es el encargado de aprobar la creación de nuevos arbitrios e impuestos que pueda someter el ADN para recabar recursos económicos para los servicios de la ciudadanía.

La ciudad, pues, en sus aspectos esenciales es administrada por instituciones dirigidas directamente por el Poder Ejecutivo.

De esta manera, aunque cada cuatro años se elige un Síndico (Poder Ejecutivo del ADN), y un cuerpo de Regidores (Poder Legislativo), el Poder del municipio en la designación, por elección o nombramiento, con plena responsabilidad y derecho permanente de control y revocación de los jueces y funcionarios comunales de todas clases, tal como se estableció en la primera gran revolución municipal: la Comuna de París, sigue siendo una ficción jurídica en el caso de la capital dominicana.

El centralismo del Poder Ejecutivo impide al Gobierno Municipal administrar el uso del suelo, orientar la apropiación de este bien, de acuerdo no sólo en el interés de los ciudadanos en términos individuales, sino con el interés del gobierno de la ciudad, en términos generales.

La exclusión del poder local de la administración efectiva del uso del suelo, no significa hoy día, ni significó durante los primeros 3 períodos del gobierno de Balaguer, que el Ejecutivo tenga un control del uso del espacio, ni-del desarrollo urbano. Es el sector privado quien se ha convertido en el verdadero promotor y orientador del proceso urbano.

Las consecuencias son obvias; una disposición del sector privado, prácticamente sin límites del bien suelo, y por ende de casi todas las actividades en espacio urbano de la ciudad capital, dicho sector lo hace de acuerdo a criterios discrecionales establecidos por el Poder Legislativo, pero en franca convivencia y conveniencia entre ambos.

De esta circunstancia se derivan otras menos gravosas para la obtención de fondos para el ADN, como veremos más adelante.

La Comisión del Plan Regulador del Ayuntamiento lo más que logra es coordinar la planificación de algunas urbanizaciones, como Sabana Perdida, Los Alcarrizos y algunos sectores de Los Mina, pero no tiene los controles requeridos para establecer criterios sobre las normas y relaciones a una estricta reglamentación del uso del suelo.

La ciudad crece, sin que las autoridades edilicias enfrenten con el debido rigor y sentido de responsabilidad las razones que impulsan hacia la especulación en el uso de su bien más preciado: el suelo edificable; y ante la más completa exclusión de la mayoría de la población de los servicios fundamentales que se supone deba tener toda aglomeración humana en un territorio con la categoría de urbana. 
Las penurias económicas en que permanentemente se encuentra la administración capitalina, la incapacidad para captar recursos, diversificando las fuentes de ingresos, pasa por necesarias modificaciones institucionales a las cuales los mismos incumbentes del ADN como el Poder Ejecutivo no parecen con la suficiente voluntad de enfrentar.

Un análisis de las fuentes de ingresos, evidencia que no sólo es necesario cambiar la forma en que se nutren las arcas del gobierno local; que se debe sólo diversificar los ingresos sino, aún más importante, se debe enfrentar con responsabilidad el problema de la ineficiencia y la irracionalidad presentes, tanto en la aplicación de las posiciones que establecen el arbitrio e impuestos a las actividades sociales y empresariales en el territorio del ADN, como en el desarrollo de iniciativas tendentes a crear otras fuentes de ingresos.

\section{La finanza municipal}

La percepción que sobre la importancia y funciones de una administración local tenga la población, es básica para poder lograr que éste contribuya de manera significativa con la finanza requerida por dicha administración para dotar a la ciudadanía de los servicios demandados.

Si no hay claridad sobre el papel de la institución edilicia difícilmente el munícipe desarrolle la debida responsabilidad cívica que lo involucre en todo lo concerniente a la vida urbana; que lo convierta en un ciudadano en el verdadero significado del término, no en un simple poblador.

De ahí la importancia recalcada anteriormente sobre la necesaria autonomía del Gobierno local para realizar una significativa función político -administrativa, porque ello es fundamental para la captación de recursos en las más variadas formas para financiar los servicios que debe prestar.

Sin embargo, la autonomía no podrá ser interpretada como una simple formalidad jurídico-normativa de las relaciones Estado-Ayuntamiento. La autonomía implica una prerrogativa institucional democráticamente desarrollada de manera consciente por la población.

Aquí radica uno de los nudos principales que se deben desatar para poder hablar con propiedad de autonomía política y financiera.

Cuando las autoridades actuales hablan de ampliar sus posibilidades para establecer arbitrios que fortalezcan sus finanzas, generalmente se olvidan de la exclusión de que es objeto la población en la toma de decisiones de parte del gobierno local, debido a su forma de elección y de gestión.

Esa exclusión deja solas a estas autoridades al momento de la exigencia de recursos para su gestión.

La población, al no tener noción clara del status jurídico-político del ADN, no puede participar con las autoridades de éste en campaña por mejores 
ingresos del cabildo. Se establece pues, un círculo vicioso. Pocos recursos para dotar de servicios significa empeoramiento de las posibilidades de incorporar a la población en la búsqueda de fuentes de financiamiento, pues se profundiza en ella la percepción de la incapacidad de sus autoridades locales de resolver sus problemas.

De manera que es básico un conocimiento a fondo de la situación económica porque atraviesa el cabildo, explicarlo a la población para encontrar en ella un aliado en la búsqueda de recursos.

Un desglose detallado de la clase de ingresos del Ayuntamiento, puede dar una idea, tanto de la insuficiencia de éstos, de la irracionalidad en cuando a la forma de captación, como de la dependencia casi absoluta que se ha creado entre la administración municipal y el Gobierno Central.

La fuente de financiamiento se encuentra fundamentalmente en el $20 \%$ del ingreso total de Rentas Internas que ésta otorga a la Liga Municipal Dominicana, la cual a su vez da un \% de dicha cifra al ADN, en relación al peso específico de su población.

Otra fuente lo constituye el subsidio extraordinario que da el Ejecutivo, además de las leyes y resoluciones de la Sala Capitular del cabildo que gravan algunas actividades empresariales, incluyendo aquellas relaciones con el uso del suelo y del consumo y uso directo e indirecto de servicios múltiples.

Fuentes de ingresos del ADN -por renglones-

A. Aquellos relacionados con la condición especial de ser un gobierno local dentro del territorio sede del gobierno central.

1. Aportes ordinarios por la Ley 140.

2. Subsidio extraordinario

3. Aportes intergubernamentales.

Anteriormente, los ingresos provenientes del área estatal eran fundamentalmente subsidios que ésta hacía al ADN, siendo variable el monto.

Las relaciones Síndico-Presidente, y las recaudaciones fiscales determinaban tanto la cantidad, como la periodicidad de la suma asignada.

Para la asignación de este subsidio era fundamental definir eventuales alianzas políticas e intereses entre los incumbentes del poder local y del poder central. No se tenía presente, entre otros, parámetros como relación, población demandante y servicios posibles que ofrecer.

Varias gestiones municipales fueron prácticamente ahogadas por el poder central ante la imposibilidad de concertar alianzas o por razones estrictamente políticas que llevaban al Presidente a obstaculizar las labores del Síndico. 
Ha sido tan así, que no pocas veces se siente en la población que es incompatible, y más aún nociva, la simultaneidad de un Síndico de un partido con un Presidente de otro. Esta percepción es un síntoma de enfermedad del sistema político dominicano y de la forma de democracia existente en este país.

Las buenas relaciones entre la sindicatura de 1982-1986, y el gobierno central del mismo período, hicieron posible la promulgación de la ley 140 en 1983, la cual establece asignar a la Liga Municipal Dominicana un 20\% del total de las recaudaciones mensuales de Rentas Internas, pues estos ingresos aumentaron a su vez de manera considerable las arcas de los Ayuntamientos principalmente el del Distrito Nacional, dado el peso de su población.

Sin embargo, esta forma de incremento de los ingresos tenía como contrapartida la limitación de las posibilidades de autonomía de las autoridades edilicias, pues con ello se fortalecían las relaciones Síndico-Presidente, en detrimento de las del munícipe-cabildo, quedando intactas las leyes 40 y 62 de 1966, las cuales impiden al ADN, establecer los arbitrios necesarios dentro de la autonomía municipal para obtener recursos para su auto-financiamiento.

La ley 140 hace posible una entrada mensual de alrededor de RD $\$ 2,000,000$, cerca de un $80 \%$ de los ingresos totales del renglón; le da más dinero que antes, pero refuerza la dependencia.

Tampoco se tocó la ley 180 de 1966, la cual establece que el Consejo Nacional de Desarrollo es el encargado del planeamiento urbano en el Distrito Nacional, y además, quien establece arbitrios, fiscaliza el presupuesto del Ayuntamiento, etc.

El síndico obtiene un aumento en sus entradas, establece buenas relaciones con el Presidente, pero no le exige a éste cambiar las ataduras del Ayuntamiento del poder central. Los cambios de fondo, los que modifican al sistema se posponen.

Actualmente hay una resolución de la Sala Capitular exigiendo la devolución de esa prerrogativa a la administración edilicia.

Los subsidios extraordinarios actualmente son muy esporádicos, dado la existencia de la ley 140, sin embargo, en octubre y diciembre de 1966, el Ejecutivo ayudó al Síndico a resolver algunos problemas, principalmente en diciembre del 1986, cuando a los empleados del Ayuntamiento se les pudo dar la regalía pascual por la intervención presidencial.

Existen algunas formas indirectas de subsidios, siendo la más usual, la construcción de edificaciones de parte del Gobierno Central para usos municipales.

También algunas instituciones del Estado, como Obras Públicas, que repara algunas calles que le interesa al gobierno que sean reparadas, así como la intervención de la Dirección Nacional de Parques Nacionales al ocuparse del 
mantenimiento y cuidado de parques ubicados en la Capital, como es el caso del Parque Mirador Sur; esto último debido a la extraña ley que faculta a una institución del gobierno central como administrador de uno de los lugares principales para el disfrute del ocio de una población local: un parque de una ciudad.

Son éstas algunas de las ambigüedades institucionales que terminan minando la autoridad del ADN, y que contribuyen a crear una idea borrosa en la ciudadanía sobre a quién le corresponde realizar determinados servicios.

La participación del Ejecutivo en la construcción o reparación de obras para usos múltiples, además del arreglo de calles o más aun, los planes de recuperación de algunos barrios mediante la demolición de casas y construcción de otras, la más de las veces lo hace con fines estrictamente políticos, por lo tanto en la planificación de estas actividades la participación de las autoridades edilicias es prácticamente nula.

De manera pues que el llamado subsidio no es más que la brecha por donde penetra el Ejecutivo en la esfera de acción que según la tradición histórica del municipio, es de estricta incumbencia de los gobiernos locales; entrando por esa brecha, el centralismo presidencialista en la vida social y política del país.

Los aportes intergubernamentales son parte de las asignaciones extraordinarias para la administración capitalina, dada su condición de sede del Ejecutivo. El más importante es aquel mediante el cual se crea un impuesto sobre el consumo de petróleo y sus derivados ya refinados de 0.15 centavos por cada galón americano que se venda en el país (Ley 409 del 26/6/83).

Es este último sustancial ingreso el cual al igual que el producido por la ley 140, fue obtenido durante la gestión del Dr. Peña Gómez, y constituye otra prueba de que el estado de las relaciones entre el Síndico y el Presidente se constituye en el termómetro que mide los niveles de ingresos del Ayuntamiento.

Conviene destacar que también esto constituye un privilegio del ADN, a todas luces irritante para otros municipios, por ejemplo Haina tiene refinerías y depósitos de carburantes, de los cuales, pese a ser un riesgo para la población, ésta no recibe ningún beneficio, ni ingreso para las arcas de su Ayuntamiento.

La forma y contenido de la ley 409 lesiona los intereses de otros gobiernos locales.

B. Ingresos ordinarios, relacionados con la actividad empresarial en el Distrito Nacional o en el empleo del contribuyente

1. Hoteles y moteles

2. Centros de diversión

3. Zona Franca del Centro de los Héroes

4. Velloneras 


\section{Salas de juegos}

\section{Bares}

\section{Restaurantes}

La Zona Franca del Centro de los Héroes paga un 5\% de sus ingresos mensuales al ADN (Ley 657). Sin embargo, amparadas en la Ley de Incentivo Industrial, las otras zonas francas no pagan impuestos, muy a pesar del usufructo de la infraestructura urbana financiada, mantenida y creada por el ADN; por ejemplo, las calles, el transporte (entre otros), que hacen posible la circulación desde su casa al establecimiento industrial que realiza el personal alli empleado, son obras del Ayuntamiento.

El cobro de impuesto a empresas comerciales se hace muchas veces de acuerdo al valor declarado en la patente de éstos.

Es sabido que la declaración de existencias y de utilidades de los comercios es disminuida considerablemente para evadir impuestos, por lo tanto la patente refleja muy poco del valor del comercio.

Esto se agrava porque los mecanismos burocráticos para el cobro de impuestos se complican de un modo tal que se hace imposible recabarlos.

En el caso de los restaurantes el cobro de impueto se hace sobre la base de la cantidad de sillas, sin embargo, no se tiene presente las ampliaciones que estos hacen, las mesas y sillas que agregan, etc.

En cuanto a los moteles éstos pagan dos pesos diarios por cada cama en uso. Obviamente es una forma de impuesto en extremo conservadora, pues no tiene presente que este tipo de comercio aumentó los precios del servicio global que ofrece, de acuerdo al aumento del costo de dicho servicio, creciendo por lo tanto las utilidades del negocio.

Mantener de manera perenne el cobro de dos pesos por cama constituye de hecho, una rebaja permanente del impuesto.

Las máquinas de juegos, de acuerdo a la resolución 60/63, pagan cuatro (4) pesos semanales. Tampoco aquí se piensa en las utilidades que éstos dejan al propietario.

C. Impuestos ordinarios por uso de servicios municipales

1. Impuesto a la propiedad

2. Arbitrio de basura

3. Agua

4. Cementerios

5. Salas de espectáculos (excluidos las de los hoteles)

6. Mesas y casetas en los mercados 


\section{Hipódromos}

8. Mataderos, etc.

Este renglón de ingresos es de suma importancia. Una racionalidad en cuanto a la forma de recabarlo, unido a un mínimo de claridad y responsabilidad en su aplicación, podría convertirlo en la más importante fuente de ingresos del ADN.

El impuesto a la propiedad en las diversas formas de existencias que ésta adquiere en un entorno urbano, puede constituirse en una de las primerísimas entradas municipales.

En varios países existe la llamada ley de radicación, la cual estipula que un edificio para uso de viviendas o comercial debe pagar un \% de su valor; esto no se aplica en nuestro país, aquí sólo se paga al momento de la construcción un impuesto al Ayuntamiento, de acuerdo al valor de los planos; otra parte se asigna a Obras Públicas.

Si no se ha sido beligerante para cobrar de manera permanente por el valor de la propiedad inmobiliaria, debido a que según autoridades municipales, se entiende que gravar la construcción iría en detrimento de la industria de la construcción.

O sea, que el sector privado es beneficiado no pagando impuestos, en detrimento de los intereses de la colectividad.

Es ésta una de las tantas manifestaciones de la especulación del capital inmobiliario. El incremento del valor de la propiedad lo genera exclusivamente el ciudadano, que es quien paga los impuestos para pagar las obras de servicios urbanos que sirvan de entornos a dicha propiedad.

Algunos especialistas en materia fiscal opinan que un impuesto sobre bienes inmobiliarios y de otro género afin, que oscile alrededor de un $1 \%$, el cual resulta moderado, podría generar unos ocho (8) o diez (10) millones de pesos al año (más o menos el doble de lo que generan los ingresos por arbitrio durante un año).

En enero de 1975 se estableció un impuesto sobre el valor del suelo urbano, Ley 115, pero parte de los recursos generados no iban al ADN, debido a mecanismos burocráticos obstruccionistas.

Se aduce que no se han instruido las formas en que el Ayuntamiento puede cobrar los impuestos que por leyes se crean para favorecerle. Por ejemplo pocas de las operaciones comerciales que se realizan son declaradas, y según cálculos conservadores de los departamentos fiscales y jurídicos del ADN, mensualmente se hacen operaciones hipotecarias de un valor aproximado de cincuenta (50) millones de pesos. La Ley 596 sobre renta e hipotecas grava con impuesto de dos (2) pesos por cada hoja del comercio o sea del contrato base de la operación. Esto no es raro, simplemente por la inexistencia de mecanismos 
adecuados para hacer cumplir esta ley. Está clara la negligencia tanto de las autoridades como de la esfera estatal. Bien podría utilizarse la declaración de bienes que todo propietario hace a Impuesto sobre la Renta; una parte (previa definición) la retendría esta institución, la otra la pasaría al Ayuntamiento.

Según la Ley 83 toda venta de muebles que se efectúe en el Distrito Nacional está gravada con 5\%; de esta cantidad, según la misma ley, el ADN debe percibir un $2.5 \%$. Todos sabemos que en esta ciudad no es difícil encontrar en la más humilde de las viviendas, barrios más pobres, equipos electrónicos, neveras y hasta muebles de cierto valor, lo cual da una idea del volumen de venta de bienes en esta Capital: esta es una de sus mayores fuentes de de ingreso, sin embargo una más estricta aplicación de la misma aumentaría considerablemente la solvencia. En lo referente al arbitrio de agua y basura existen no sólo problemas de ineficiencia y poco sentido cívico de los usuarios, sino cuestiones del orden institucional que expresa duplicidad de funciones.

El ADN desde siempre tuvo, entre sus atribuciones, la administración del suministro de agua a la población capitaleña. Sin embargo, durante el gobierno de Balaguer, en los 12 primeros años de su gestión, entre otras medidas, se creó la hoy llamada Corporación de Acueducto y Alcantarillado de Santo Domingo (CAASD), la cual se arroga el derecho de la administración y del suministro de agua del Distrito Nacional, y de la basura, cobrándola mediante una factura única. (El Ayuntamiento la recoge, la CAASD, institución autónoma, la cobra).

La resolución 1-75 establece el pago del servicio de recogida de basura según el volumen de desperdicio, pero los criterios para determinarlo son totalmente arbitrarios. Por ejemplo, se cobra a los hoteles sin tomar en cuenta el número de actividades que en ellos realice (casinos, salas de espectáculos, números de bares y restaurantes que tengan, etc.).

Los restaurantes pagan de acuerdo al número de sillas, no de acuerdo a lo que facturen.

Las viviendas pagan según el barrio. La mitad de los usuarios no pagan el servicio de recogida de sus desperdicios sólidos.

En lo que respecta al arbitrio sobre el consumo del agua existen varios problemas.

Cuando se iba a hacer la Presa Madrigal, con préstamos del BID, una de las exigencias para éste llegar a acuerdos de financiamientos era que se debía instalar un contrador en las casas de los usuarios, para establecer un cobro del suministro del líquido según el consumo, además para obligar al usuario a disminuir el consumo.

Se instalaron los contadores en la mayoría de los barrios residenciales, pero la práctica es cobrar de acuerdo a la zona. El gasto hecho para la instalación 
de los contadores ha sido inútil, por lo menos hasta ahora. Se ha mejorado en el cobro del líquido, pero todavía existen problemas serios.

La estructura de los barrios más pobres, dificulta establecer un control sobre los usuarios. Se ha podido comprobar que existe alrededor de un $50 \%$ de los usuarios registrados que no pagan agua; al resto, de casi esa misma proporción no llega el líquido.

El pago del agua se realiza en las oficinas instaladas por la CAASD para tales fines, y las oficinas privadas. Las primeras cobran un $3 \%$ de lo recaudado al ADN, las segundas un $4 \%$, o sea $7 \%$ de lo recaudado se queda entre el sector estatal y el privado.

Esa pérdida se agrava por la lentitud con que la CAASD envía el dinero de la recaudación al Ayuntamiento, llegando por momento a adeudarle $\$ 600,000$ a la entidad edilicia.

El uso de los cementerios y los servicios de enterramientos, produce ingresos fijos por alrededor de 525 mil pesos y los gastos por concepto del personal encargado del servicio son alrededor de [...]

Esa desproporción es más acentuada en lo relativo al alquiler de las mesas y casetas de los mercados.

Aquí no sólo es significante lo que estos negocios pagan de impuestos con relación al ingreso que perciben, sino que resulta alarmante la desaprensión exhibida por las autoridades municipales.

He visitado los mercados, he hablado con los dueños de varias mesas y he constatado que por ejemplo, en el Mercado del Ensanche Honduras hay mesas que pagan la insignificante cantidad de 75 centavos, 25 centavos más de lo que pagaban hace 21 años cuando se construyó el mercado.

Casetas de expendio de provisiones en general, pagan de 3 a 5 pesos a pesar de tener ganancias de más de 1,180 y 1,350 diarios. Las mesas se venden graciosamente de uno a otro vendedor por cantidades que superan los $\$ 300$ pesos, según el tipo de mesa, sin que haya ningún control de parte de las autoridades.

En el mercado. de la Avenida Mella hay una tienda de regalos la cual paga $\$ 5$ diarios, sin embargo, la existencia de mercancías es de $\$ 300,000$ pesos y factura entre 7 y 8 mil pesos diarios, lo cual contrasta con los 417 mil recaudados por las operaciones de todos los mercados en el 1984.

Actualmente hay tres dueños de negocios de ese mismo ramo que venden sus puestos por 50 mil pesos cada uno.

Claro que es fácil determinar quiénes son, y dónde están, sólo falta la voluntad de encontrarlos y someterlos al pago de impuestos que vayan en consecuencia con sus ingresos. 
Manteniendo esa situación pierden toda credibilidad las quejas de autoridades municipales cuando expresan la enorme desproporción entre los gastos para la operación de limpieza de los mercados y los exiguos recursos por conceptos impositivos que estos mercados producen.

Un último comentario en dos casos sobre los renglones de impuestos, para demostrar no sólo una deficiencia que parece ser calculada, no por ambigüedad legal, no por simple irracional, sino para favorecer al sector privado en su uso de la ciudad para reproducir su capital.

El primero es la ley que grava el expendio de carne en el Distrito Nacional. Según esta ley, todo matadero municipal debe pagar como tasa de un (1) centavo por cada libra de carne puesta al mercado. Hay un matadero estatal, que antes era de Trujillo, y como la referida resolución habla de matadero municipal los propietarios de los demás interpretan de manera acomodaticia diciendo que son sólo los mataderos municipales los gravados con la ley, y por tanto ellos se abstienen de pagar, dejando el ADN de percibir alrededor de un (1) millón de pesos al año.

Por resolución No. 2069, los espectáculos artísticos pagan un 7.0\% al cabildo, pero cuando se presentan artistas extranjeros, que es cuando mayores son los ingresos, no se cobra ningún impuesto, pues la ley de Incentivo Turístico protege al empresario de la aplicación de dicha resolución.

E. Impuestos al Uso Indirecto de la Infraestructura Urbana

1. Placa de vehículos, tanto de tracción mecánica como animal.

2. Vehículos privados, del transporte urbano

3. Solares yermos

4. Licencias para construcción

5. Letreros lumínicos

6. Vallas

7. Chimichurris y venduteros ambulantes, etc.

Hemos recogido muchas informaciones acerca de las operaciones de los chimichurris, de quienes son propietarios y cuánto ganan, y sụ relación con el sector formal de la economía. Los dueños de estos negocios suelen ser personas con ingresos fijos, producto de trabajos realizados en el sector formal; y son operados por trabajadores asalariados (una media de 2). La mayoría de estos negocios están ubicados en la parte oeste de la Capital, aquella donde se concentran las familias de mayores ingresos. Hay chimichurris que dejan una ganancia neta de $\$ 6,000$ pesos mensuales.

Pocos pagan luz eléctrica regularmente, ni pagan arbitrio de basura. En preguntas formuladas a los dueños y vendedores, éstos dan cuenta de las visitas hechas por inspectores a lugares donde se encuentran ubicados, notifican el 
negocio, á veces cobran el impuesto y otras (no pocas) jamás vuelven a cobrar arbitrio.

En el curso de esta exposición hemos hablado de duplicidad, ambigüedad institucional, de relación Estado-Cabildo; también de falta de claridad del rol de este último.

En la búsqueda desesperada de obtener recursos, a veces (como en el caso que comentamos a continuación) se incurre no en confusión de rol, sino en simple acto de dolo a la propiedad de la comunidad, siendo alarmante el caso, pues quien lo comete es el propio Ayuntamiento.

La Ley 675 sobre construcciones de urbanizaciones del sector privado, obliga a las compañías inmobiliarias a donar al ADN una cierta cantidad del suelo edificable para ser dedicado a la necesaria área verde de la urbanización por construir. Esto constituye en sí un cierto impuesto a la propiedad por uso indirecto de infraestructura urbana, pues constituye una forma de bien que se le retribuye al ciudadano.

Sin embargo, a veces, cuando el cabildo está muy urgido de recursos, vende esas áreas a particulares para resolver problemas económicos, coincidiendo pues en esa absurda especulación del suelo con las compañías inmobiliarias, las cuales también a veces una vez terminadas y vendidas las edificaciones, proceden a construir sobre las áreas verdes inicialmente dejadas para uso exclusivo de área de esparcimiento.

Las litis judiciales entre usuario-vendedor son bastante frecuentes según informes obtenidos en la Direccián de Asuntos Jurídicos del ADN.

La especulacián y abuso contra el usuario es alarmante. Cuando un usuario compra un terreno, diciéndole que su entorno tendrá tal o cual servicio se está estableciendo una renta diferencial sobre el terreno, la cual es pagada por el comprador al momento de firmar su contrato de compra y venta; o que objetivamente éste paga las áreas verdes, pero luego inescrupulosamente es despojado de ella, sea por el vendedor, o, lo que es más grave, a veces por su gobierno local para fines de obtención de recursos. Esta última es sólo concebible en una ciuad donde la conciencia dẹ los derechos cívicos esté muy poco desarrollada en la población, en una ciudad con limitada tendencia a la organización para la defensa de los intereses colectivos.

Frecuentemente existen otras fuentes de ingresos, pero su aporte al pres̀upuesto podría ser significativo de pagarse puntualmente. En el caso de las salas de cine, éstas pagan 7\% de lo recaudado, aunque hay una tendencia a disminuir la cantidad por personas. A modo de ejemplo el Cine Triple III tiene en su tanda diaria a las 5 p.m. un promedio de 56 personas, 87 a las 7 p.m.; y 93 a las 9 p.m. El Triple IV tiene unas 56 personas, a las 5 p.m.; 87 las 7 p.m. y 96 a las 9 p.m. El promedio del precio de las boletas en las tres tandas es actualmente de cuatro 
pesos (4), lo cual significa una entrada bruta diaria de $\$ 944$ pesos, correspondiéndole al ADN \$66.08.

Algunos cines son contribuyentes morosos, y en varias ocasiones la Sección de Impuestos de Cabildo ha ordenado el cierre de éstos para obligarlos a pagar su contribución por el uso de la infraestructura urbana.

En cuanto a vallas, letreros lumínicos, etc., el pago no es regular aunque es justo reconocer, de más en más se tiende a mejorar el pago del arbitrio.

\section{Otros impuestos}

\section{A. Donaciones}

Este renglón abarca financiamientos a planes de desarrollo institucional hechos por el BID y otras entidades extranjeras. También contribuyen gobiernos locales y estados extranjeros, tanto con maquinarias y equipos, como con dinero en efectivo. En ese mismo renglón contribuye aunque de manera poco significativa, al sector privado del país.

Para el presupuesto de 1985 se esperaba un ingreso en este renglón, de 6.0 millones de pesos, como contribucián del Gobierno Central al mantenimiento vial de la ciudad capital.

\section{B. Aportes de los Funcionarios del ADN}

Un vicio institucional (para darle un calificativo) se convierte en fuente de financiamiento. Se trata de la donación (impuesto compulsivo) que hacen los empleados y funcionarios del Cabildo.

A quienes devengan un salario hasta $\$ 399$ pesos se hace un descuento de un $2 \%$ y otro a aquellos que ganan más de $\$ 400$ pesos mensuales.

Este renglón aporta al ADN \$306,460 pesos, según presupuesto de 1985. Pagarlo significa una suerte de impuesto para mantener el empleo. Por último, como ingreso se consigna los préstamos navideños del Banco de Reservas hechos a los funcionarios y empleados.

\section{Ingresos globales del ADN}

Según el informe del Síndico saliente, en su fin de gestión, el 16 de agosto de 1986, la recaudación del fin de la gestión fue de \$122,176 (informe del Dr. J. F. Peña Gómez), de esa suma el 39\% de lo recaudado fue en el renglón clasificado ingreso no tributario, o sea aquellos obtenidos principalmente por la ley 140 , la cual como ya dijimos, consagra el $20 \%$ de las recaudaciones de Rentas Internas a favor de los municipios del país. Ello da una idea de la precariedad financiera en que vivian estas entidades antes de 1984.

El presupuesto del Ayuntamiento del Distrito Nacional para el año de 1987, es de 60.0 millones de pesos. Las recaudaciones tributarias mensuales serán de unos 50,060 mil pesos, los cuales representarían unos 72.0 mil pesos anuales. 
Las asignaciones por la ley 140 serán de unos 2.0 millones de pesos; éstos más las donaciones y subsidios llegarían a unos 33.0 millones de pesos.

Según la Tesorería del Cabildo, la proyección de los ingresos y egresos apunta hacia un déficit presupuestal de 27.0 millones, o sea casi un $50 \%$ de los gastos para cubrir las necesidades de servicio a la comunidad, según el magro presupuesto del ADN.

Una lectura de los ingresos, y los egresos, puede dar una idea de la precariedad económica en que se desenvuelve el Cabildo para satisfacer una población que en 1990 llegará a 2.0 millones de habitantes.

\section{Algunas posibles modificaciones}

1. De orden político. Mayor poder a la institución municipal, pero un poder no burocrático, no simplemente abogando por mayor autonomía de las autoridades edilicias, sino una integracián del munícipe a la vida ciudadana, incorporando de manera institucional y con real poder a las organizaciones municipales de base: Junta de Vecinos, Comités Barriales, y modificar las alcaldías haciendo de éstas órganos representativos reales de la comunidad.

2. Para incorporar a la vida municipal se debe modificar la forma de elección de las autoridades municipales, haciendo cumplir el precepto de las autoridades municipales, haciendo cumplir el precepto constitucional de que la elección de ésta debe constituir un acto de sufragio separado de las elecciones presidenciales, o sea estableciendo fechas diferentes en la elección del presidente y los miembros de las cámaras y de los síndicos y los regidores.

3. Una modernización de la legislacián tributaria nacional y local, la cual haga más rigurosa la captación de recursos gravando la propiedad, y que cree mecanismos que agilicen el pago de impuestos municipales e impidan que quienes deban hacerlo lo eviten por la inexistencia de dichos mecanismos. Se debe aplicar la ley 115 de 1975, luego de una mayor claridad de la misma.

El personal de la institución consumió durante el período 1982-1984, el $52 \%$ del presupuesto. El personal de ADN nombrado y nominal es de 6,971 (en 1987). No hemos hecho un estudio sobre el servicio demandado, pero por las quejas hechas por el Síndico sobre la necesidad de un mayor rendimiento del personal bajo su dirección, y porque como es de todos conocido, el ADN es una de las fuentes de empleo para aquellas personas a quienes se les deben favores políticos, y para pagar sus lealtades de grupos, se podría preguntar si el número es o no muy alto.

De todos modos, esto es un problema secundario, el principal sigue siendo las limitaciones económicas reales porque atraviesa el primer municipio del país, y el fondo de éste radica en su dependencia económica, en la carencia de una autonomía que le permita gravar con impuestos las actividades 
empresariales que usufructúan la infraestructura urbana para reproducir su capital, a la propiedad urbana, al uso del suelo por particulares, etc.

Sólo así se puede invertir la tendencia del déficit presupuestario, el cual se traduce en déficit en los servicios.

Se requiere, pues, un cambio institucional a nivel del sistema político dominicano para poder ir al centro del problema.

4. Eliminación de las ambigüedades institucionales en materia de cobro de arbitrio, reclamando la absoluta incumbencia del ADN en materia de cobro de impuesto a las actividades realizadas en su ámbito territorial.

5. Eliminación de la práctica del Gobierno Central de constituir organismos, comisiones y equipos de asesores con jurisdicción, para asumir de manera directa la política de desarrollo urbano de la Capital. Con esa práctica, de manera impune, terrenos agrícolas pasan a ser edificables, zonas urbanizadas se crean siguiendo criterios de estricto interés político o especulativo, con escaso o ningún impuesto municipal, y lo que es peor, creando nuevas cargas al ADN.

6. Establecer contribuciones especiales para la ejecución, ampliación o rehabilitación de obras de fundamental importancia para resolver problemas de la comunidad. Por ejemplo, el ADN no tiene dinero para dotar a la ciudad de un alcantarillado pluvial que resuelva el problema de las inundaciones. La solucián de éste sólo es posible con un presupuesto que resulte ser casi la mitad del presupuesto nacional, en este caso, previa coordinación con Rentas Internas se podría establecer una contribución extraordinaria, bien podría ser, en este caso, la aplicación del proyecto de impuesto a los vehículos que entran a la ciudad.

7. Eliminación de la ley 180 la cual faculta al Consejo Nacional de Planificación para aprobar en última instancia el establecimiento de arbitrios, impuestos y tasas, devolviendo esta facultad al Poder Legislativo del Cabildo: La Sala Capitular, tal como se sugiere en el proyecto de reforma a la Ley Orgánica del Distrito Nacional.

8. Solicitar préstamos a entidades financieras internacionales para implementar un programa de reorganización administrativa del ADN depurando su personal, optimizando su rendimiento.

9. Ejecutar una campaña cívica exponiendo a la ciudadanía todos los servicios que ofrece el $A D N$ y la necesidad de fuentes de ingresos para ejecutarlos. Aclarando por cuáles servicios, y actividades empresariales se debe pagar una tasa. 


\section{APENDICE}

La precariedad de los servicios en la ciudad de Santo Domingo no sólo se acentúa por la falta de recursos, sino por razones políticas, y sobre todo de institucionales. Una lectura al siguiente cuadro da una idea bastante aproximada del problema.

\section{PRINCIPALES SERVICIOS URBANOS}

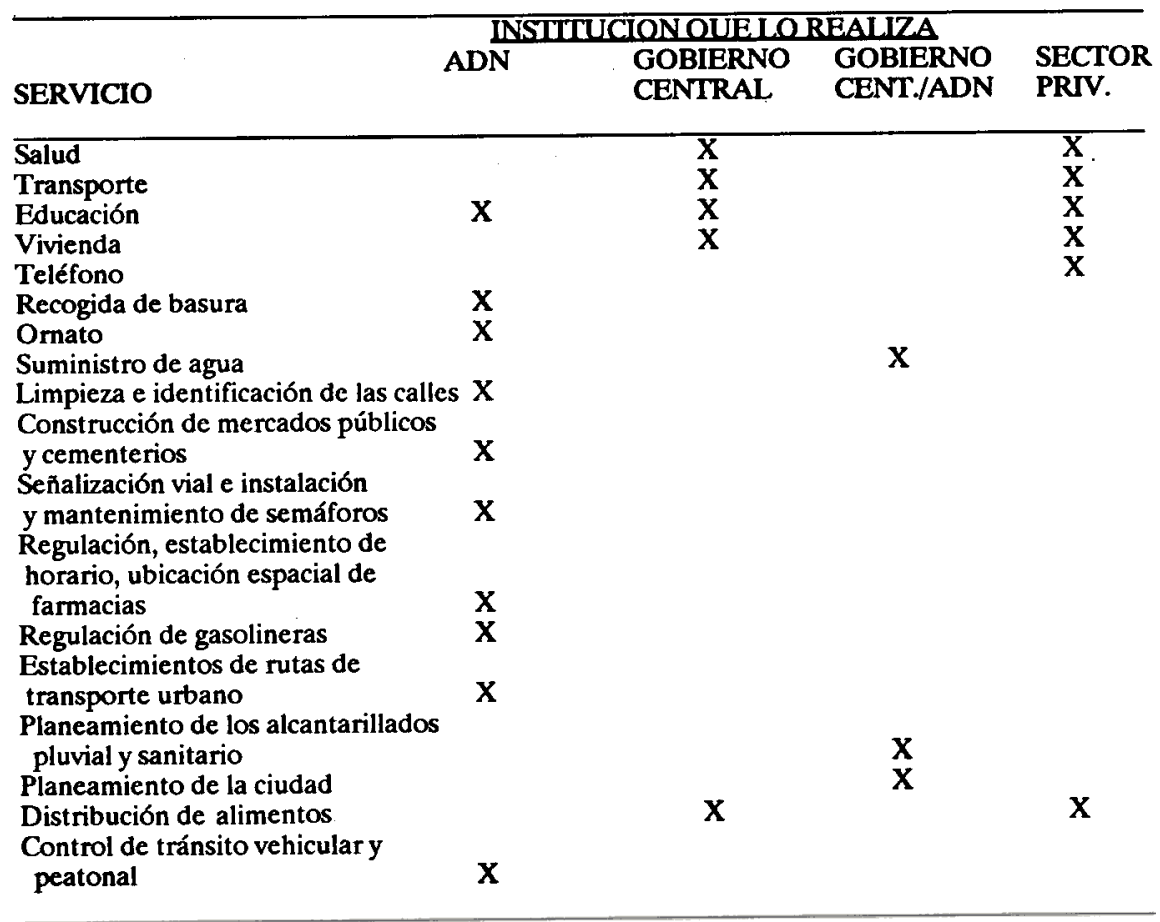

La educación: tal como lo consignan las atribuciones del Cabildo, éste debe velar porque del pan de la enseñanza no sea excluido ningún ciudadano. Existen barrios como el de Villa Juana, con una población de 42, o 73 mil habitantes y no tiene ni un solo liceo secundario, ninguna biblioteca pública, y sólo dos centros de enseñanza primaria. El deterioro de la enseñanza pública es mayor cada año. 
El Estado se ha sustraído de la responsabilidad de la educación. El sector privado tiene una incidencia casi absoluta en tan importante servicio. No existen maternales públicos donde el trabajador pueda dejar a sus hijos; los que existen son privados.

Si el ADN no tiene medios para dar servicios a los sectores populares en renglones tan vitales como la recogida de desechos sólidos, transporte, agua, etc., mucho menos lo tendrá para maternales. La privatización de la enseñanza media, y sobre todo superior, parece ser un hecho irreversible.

Vivienda: Un bien cada día más caro y sobre el cual mayor especulación se realiza en esta ciudad. De los planes de construcción de vivienda que son realizados por el gobierno y el sector privado, del tipo de construcción que se realiza están excluidos cerca de un $90 \%$ de la población, ya que por sus ingresos no califican como adquirientes de viviendas. El sector público participa construyendo la mayor parte (por no decir de manera completa) de las viviendas populares. El sector privado tiene un control casi absoluto en este renglón.

El ADN prácticamente no participa en la oferta del servicio. Sin embargo, poco hace para evitar el incremento del costo del suelo, nunca embarga terrenos para la construcción de viviendas populares, jamás se pronuncia sobre la especulación edilicia y contra la carestía de vivienda.

Basura: La ineficiencia del ADN para dar un servicio de recogida de desechos sólidos, ha provocado que en los medios de comunicación comience a hablarse de la posibilidad de que el sector privado se involucre en la oferta del servicio con criterios comerciales.

De hecho la falta de equipo del ADN, lo obliga a alquilar flotas de camiones para el transporte de basura hacia los vertederos, y otros servicios. En 1985 se gastó la suma de $\$ 488.535$ pesos en ese renglón.

En la estructura de los barrios marginados, por lo accidentada que son sus calles, resulta casi imposible la recogida de basura.

También en las cuarterías se usa mucho la práctica de hacer verțederos improvisados, y es relativamente poca la basura que sacan a las calles para ser recogida.

Suministro de agua: Anteriormente se explicó la ambigüedad institucional que existe entre la CAASD y el ADN.

La deficiencia en cuanto al servicio de este indispensable líquido provoca algunos problemas nada despreciables desde el punto de vista económico.

El agua corriente es almacenada en cisternas e impulsada por bombas de fabricación extranjera. Esto significa: 1) Casi, por no decir todas las casas y edificios de apartamentos de los barrios residenciales tienen cisternas. 2) Su instalación constituye un uso de productos de importación, y por tanto de fuga de divisa, de significativa importancia, pues la cantidad de divisas con que 
cuenta el país es cada día más limitada. 3) Por períodos, el agua no llega ni siquiera a los barrios donde el suministro es bastante frecuente, esto ha provocado la proliferación de varias compañías que se dedican a la venta de agua obtenida en pozos filtrantes que se alimentan de las corrientes de agua subterránea de la ciudad, la ciudad, la cual según precepto constitucional es de uso público. Se debería poner una alta tasa por ese uso.

Transporte: Es éste uno de los servicios urbanos más deficientes. Cerca de un $90 \%$ de la población actual de la ciudad tiene un ingreso que lo imposibilita de poder adquirir un automóvil privado, por lo tanto ese mismo porciento se convierte en el usuario del transporte público.

Este es operado. por los llamados carros de concho, por los autobuses, ahora por el llamado motoconcho, y por ONATRATE.

Los carros de concho y los autobuses son propiedad de choferes individuales y de un sinnúmero de compañías privadas. Estos manejan prácticamente a su antojo el servicio de transporte.

El ADN traza las rutas, pero el recorrido de éstas está a la absoluta discrecionalidad del chofer. Este corta, la divide, encareciéndola inescrupulosamente ante los inutiles reclamos de los usuarios.

El transporte resulta caro, incómodo y riesgoso para el usuario a nivel individual, y escandalosamente caro para el país en general, pues gasta una enorme cantidad de combustible; provocan cerca de un $80 \%$ de los entaponamientos en las redes viales de la ciudad.

La ciudad crece de manera inversamente proporcional al incremento de vehículos para el transporte colectivo.

Son muchos los barrios que no tienen servicio de transporte, otros tienen una ruta de autobús que pasa con poca frecuencia, y hasta las 10 de la noche, a lo sumo.

Para un trabajador que devenga el salario mínimo, pagar 35 centavos de transporte resulta ser aproximada de $\$ 14.70$ al mes, lo que significa un $6.0 \%$ de su salario.

Parques de recreación y cultura: El ADN cobra el servicio, pero la Dirección de Parques Nacionales, bajo la dependencia del gobierno central controla, en cuanto a mantenimiento, algunos de los parques (caso Zoológico, Mirador Sur, etc.) por incapacidad del Cabildo de mantenerlos. También la Secretaría de Deportes, Educación Física y Recreación (SEDEFIR), opera algunos parques, por ejemplo Parque Olímpico.

Correo: Servicio más que deficiente. Actualmente el sector privado incursiona en la oferta del servicio con fines estrictamente comerciales. 


\section{LITERATURA CITADA}

Informe del Dr. José Francisco Peña Gómez al concluir su gestión el 16 de agosto de 1986.

Presupuesto del ADN para el año 1985.

Liga Municipal Dominicana.

Actas de la Sala Capitular.

República Dominicana en Cifras, Vol. XIII. Santo Domingo, Septiembre de 1986.

Organismos asesores interinstitucionales del sector público. Secretariado Técnico de la Presidencia.

Censo Nacional de Población y Vivienda 1981. Vol. I, resultados definitivos del Distrito Nacional (dic. 1985).

El proceso de urbanización en la República Dominicana. Secretariado Técnico de la Presidencia, nov. 1983.

Padco-Borrel y Asociados: Estudios sobre el desarrollo urbano de la ciudad de Santo Domingo. 1978.

Castelles, Manuel. La ciudad y las masas: sociología de los movimientos sociales urbanos. Alianza Editorial, Madrid, 1986.

Castelles, Manuel. Crisis urbana y cambio social. Siglo XXI, México, 1981.

Problemas de las áreas metropolitanas. Autores varios; Instituto Administración Local. Madrid, 1976.

Manual de Organización del Gobierno, ONAP, Santo Domingo. 